\title{
A long-term follow-up of workers exposed to beryllium
}

\author{
J E COTES, J C GILSON, ${ }^{*}$ C B MCKERROW,$\dagger$ AND P D OLDHAM
}

From the Medical Research Council Pneumoconiosis Unit, Llandough Hospital, Penarth, S Glamorgan CF6 $I X W, U K$

ABSTRACT The relationship of features of beryllium disease to the estimated exposure to beryllium has been investigated over a 30 -year period at a factory manufacturing beryllium products. The factory opened in 1952 . Of the 146 men who had worked there for more than six months up to 1963 , $89 \%$ were seen at that time and were followed up in 1973 . The nine who continued to work in the factory and those who were engaged subsequently were examined in 1977 . On each occasion a clinical interview, occupational history, chest radiograph, and assessment of lung function were carried out. The findings of the main survey were related to the beryllium content of the dust measured by mass spectrometry for 1952-60 when over 3000 determinations were made. In no part of the plant did the estimated average daily exposure exceed $2 \mu \mathrm{g} \mathrm{m}^{-3}$, and only $9 \%$ of individual determinations exceeded this level. Twenty determinations exceeded $25 \mu \mathrm{g} \mathrm{m}^{-3}$. During the period under review, four men developed the clinical, radiographic, and physiological features of beryllium disease. Two men acquired abnormal chest radiographs consistent with beryllium disease but without other features, and one developed probable beryllium disease despite the diagnosis not being confirmed at necropsy. The affected men were all exposed to beryllium oxide or hydroxide but in a wide range of estimated doses. In six the changes developed after exposure had ceased; trigger factors including patch testing may have contributed to their illness. Seventeen men recalled episodes of brief exposure to high concentrations of dust, two developed pneumonitis from which they recovered completely, and one developed chronic beryllium disease after a further 23 years' exposure. In subjects without clinical or radiographic evidence of disease no convincing evidence was obtained for any association between the lung function and the estimated exposure to beryllium.

The standard of hygiene for personnel working with beryllium was established in 1944 by the United States Atomic Energy Commission and subsequently accepted by the American Conference of Government Industrial Hygienists (ACGIH). It comprised a threshold limit for regular work of eight hours a day of $2 \mu \mathrm{g} \mathrm{m}^{-3}$ as a time-weighted average, a ceiling for periods of 30 minutes of $25 \mu \mathrm{g} \mathrm{m}^{-3}$, and an upper limit for a single determination of $100 \mu \mathrm{g} \mathrm{m}^{-3}$. Also established was a general atmosphere threshold for air in the vicinity of a beryllium plant of $0.01 \mu \mathrm{g}$ $\mathrm{m}^{-3}$. The ceiling was derived from experience of cases of acute disease. The factory threshold limit was an

*Present address: Hembury Hill Farm, Honiton, Devon.

† Dr McKerrow died in 1972.

Received 18 January 1982

Accepted 1 March 1982 estimate based on the dose-response relationship for other toxic metals but reduced by a factor of 2 to allow for error. ${ }^{\prime}$ The adoption of these standards materially reduced the incidence of beryllium disease,${ }^{2}$ but cases continued to occur. Some resulted from recognised incidents or injuries leading to implantation. Others reflected long-term exposure to concentrations of beryllium, which in several instances were above the threshold limit. Little information is available, however, on the dose-response relationship so it is not at present known if the standard is adequate or should be revised. In 1963 an opportunity arose to survey past and present workers in a factory where exposure to beryllium had occurred since 1952; the results of a large number of measurements of airborne beryllium were available for analysis, and the management and work-force were willing and able to co-operate whole-heartedly in the study that 
took place at a time when the factory was expected to close. In the event it remained open, and the total duration of follow-up is now 30 years. The findings on this almost complete population of workers throw light on the relationship of the dose of beryllium, when achieved by long exposure to low concentrations, to the development of chronic disease; a subsequent paper (J E Cotes, K McConnochie, in preparation) will describe some clinical aspects including the reversibility of the physiological and radiographic features. The findings have been reported briefly elsewhere. ${ }^{34}$

\section{Background}

From 1952 to 1963 the factory refined beryllium ore to produce beryllium hydroxide, which was then either reduced to beryllium metal or calcined to form beryllium oxide. After 1963 the main raw material was beryllium oxide. The process of refinement entailed the debagging and crushing of the ore, which was then mixed with sodium silicofluoride and soda ash to make brickettes. These were heated in a kiln to $750^{\circ} \mathrm{C}$, then crushed and leached with water to extract the beryllium hydroxide. Part of the latter was reduced by further heating to form beryllium metal which was then poured into moulds. Beryllium oxide was obtained by calcining; the oxide was used for the manufacture of tubes, solid objects including mountings for electrical components, and crucibles by the processes of slip casting and cold and hot pressing.

Dust containing beryllium was produced during most of the processes; protection was by exhaust ventilation. Very few employees wore masks. Potential employees were examined medically before being engaged by the company; they subsequently had periodic examinations including annual chest radiographs. Both these and the sick quarter records were scrutinised as part of the present study. Death certificates of the men who had died up to 1973 were also seen. The subsequent course of men who were alive in 1973 will be reported separately.

\section{Population}

From 1952 to 1963206 people were taken on to the books of the factory: 146 were men who by $1963 \mathrm{had}$ individually worked for more than six months, and they constituted the defined population. One hundred and thirty $(89 \%)$ of this group were seen clinically, a chest $x$-ray film was taken, and in the case of all but one man, pulmonary function was measured. Eight from the defined group died before 1963 , but there was no evidence to suggest that exposure to beryllium might have contributed to their
Table 1 Population for study: subcategories of the 206 employees 1952-60

\begin{tabular}{lcc}
\hline & $1952-63$ & $1963-73$ \\
\hline Men & \multicolumn{2}{c}{} \\
Died before survey & 23 & - \\
Worked under 6 months & 10 & - \\
Records incomplete & 146 & 130 \\
Defined population & 6 & 5 \\
$\quad$ Refusals & 5 & 4 \\
$\quad$ Lost & 5 & - \\
Too ill or too old & - & 15 \\
Died & 130 & 106 \\
Seen & 19 & - \\
Women & & \\
\hline
\end{tabular}

deaths. Not included in the study were subjects who had worked for under six months, those with incomplete records, and the female employees of whom there were relatively few. The women were seen and assessed in the same way as the men but none showed any evidence of beryllium disease. Table 1 gives the distribution of the original 206 employees between the different categories.

In 1973 the defined population of 130 men was followed up. Fifteen were found to have died since the earlier study and nine could not be contacted: measurements were repeated on the remaining 106. In 1977 the eight men still working in the factory and one ex-employee, together with 24 out of 25 employees who had been taken on since 1963, and 14 out of 17 ex-employees taken on since 1963 were seen and assessed in the same way. All assessments were made at the MRC Pneumoconiosis Unit near Cardiff.

\section{Methods}

CLINICAL

These comprised the short MRC questionnaire on respiratory symptoms, ${ }^{5}$ a full occupational history, a brief clinical history, and clinical examination of the cardiorespiratory system.

\section{RADIOGRAPHY}

A posteroanterior chest radiograph was obtained at each attendance. At the time this was read for pneumoconiosis and pre-employment and periodic chest radiographs taken during employment were scrutinised. After the 1973 and 1977 surveys the radiographs were reread for small round and irregular opacities using the extended ILO classification. ${ }^{6}$ The films were then classified under three headings: (1) those that were indubitably normal, (2) those where there was abnormality that was definitely or probably not related to exposure to beryllium, the former group including subjects in whom the abnormality was present in the pre-employment film, and (3) 
those in whom beryllium disease was apparently present in 1963 or had developed subsequently.

\section{RESPIRATORY FUNCTION}

The assessment comprised the forced expiratory volume and vital capacity by spirometry, the total lung capacity and its subdivisions by the closed circuit helium dilution method, the transfer factor (diffusing capacity) for the lung by the single breath carbon monoxide method using an inspired carbon monoxide concentration of approximately $0.3 \%$, the diffusing capacity of the alveolar capillary membrane and the volume of the blood in the lung capillaries by the method of Roughton and Forster ${ }^{7}$ but without allowance for the back tension of carbon monoxide in the alveolar capillary plasma, the static lung compliance by the volume-pressure method using an oesophageal catheter tipped with a latex balloon containing $0.4 \mathrm{ml}$ of air, and the physiological response to submaximal exercise; the latter was expressed as the ventilation and the cardiac frequency at the uptake of oxygen of $67 \mathrm{mmol} \mathrm{min}^{-1}$ $\left(1.51 \mathrm{~min}^{-1}\right)$ and the tidal volume at a minute volume of $301 \mathrm{~min}^{-1}$. In 1963 exercise was on a treadmill at a speed of $60 \mathrm{~m} \mathrm{~min}^{-1}(2.5 \mathrm{mph})$ and inclines of zero and $10 \%$. In 1973 exercise was on a cycle ergometer, the rate of work being increased progressively from 0 to 100 watts at the rate of $10 \mathrm{w} \mathrm{min}{ }^{-1}$. The other methods were essentially the same on the two occasions; they are described in detail elsewhere together with the reference values. ${ }^{8}$ For the purpose of analysis the diffusing capacity of the alveolar membrane and the volume of blood in the lung capillaries were treated in the reciprocal form in which they were derived (1/Dm and $1 / \mathrm{Vc}$ respectively). The $5 \%$ level of probability was accepted as significant.

\section{ENVIRONMENTAL EXPOSURE}

Quantitative estimates of beryllium exposure were obtained from the extensive records of total airborne dust concentrations over the period 1952 to 1960 plus information from the management and men as to where each employee had worked during his time with the company. Airborne concentrations of beryllium, expressed as $\mathrm{BeO}$, were obtained from weighed filter-paper samples collected over periods of one to four hours. For each sample site the concentrations were plotted by calendar date on logarithmic graph paper, and the geometric mean concentration for each year was estimated by eye. Where there were gaps in the record guesses were made either continuing an apparent trend or identical with the adjacent figures or, occasionally (as for the main office), equal to the average for the available figures; these varied in number from nine in the *That for slipcasting bay is available on request from JEC. development laboratory to over 2000 in the slipcasting bay.* Similarly, an overall figure was obtained for each process and for the work as a whole.

The dust exposure of each man for each month of his employment up to 1963 was estimated from the annual dust concentration for each process. If several processes were worked concurrently the timeweighted mean concentration was used. For the month when a change in job occurred the man was assumed to have worked half the month in each. Four indices of exposure were obtained for each man: (1) the total number of months in beryllium, (2) the total dose-that is, the sum of the estimated dust concentrations to which the man was exposed for each year of employment, (3) the integrated dosethat is, the sum of the products of the annual dust concentrations and the time up to 1963 during which each of them had exerted an effect, and (4) an empirical clinical grading of exposure; the grades are given in table 2.

After 1963 the information was less extensive, and estimates of exposure could not be made from this time onwards.

\section{Table 2 Empirical grading of exposure to beryllium}

\begin{tabular}{ll}
\hline Grade & Description \\
\hline 0 & Not in factory-for instance, in office or canteen \\
1 & Time spent in factory or laundry $<50 \%$ \\
2 & Time spent in factory or laundry $>50 \%$ \\
3 & Grade 2 plus remembered episode of high exposure
\end{tabular}

\section{Results}

\section{ENVIRONMENTAL MEASUREMENTS}

Table 3 gives the estimated mean dust concentrations for the nine years $1952-60$, together with the number of observations and the number that exceeded the threshold limit of $2 \mu \mathrm{g} \mathrm{m}^{-3}$ and the ceiling of $25 \mu \mathrm{g}$ $\mathrm{m}^{-3}$. Two readings exceeded by a small amount the upper limit of $100 \mu \mathrm{g} \mathrm{m}^{-3}$. With one exception which reflected a single determination, the mean values were all under $2 \cdot 0 \mu \mathrm{g} \mathrm{m}^{-3}$. Apart from the slip-casting bay where there was a significant increase the concentrations show a downward trend with time; this is reflected in the estimate for the whole works where the concentration in 1960 was about half of what it was in 1952. The higher concentrations were observed in relation to the production of beryllium hydroxide and of beryllium metal; the 20 instances of peak concentration in excess of $25 \mu \mathrm{g} \mathrm{m}^{-3}$ almost all occurred in these areas. High concentrations were also found in the locker and changing rooms, the laundry, and the canteen. Low concentrations were observed in the fitting shop, the laboratory, and the main and drawing offices. 
Table 3 Dust levels in the factory (1952-60)

\begin{tabular}{|c|c|c|c|c|c|}
\hline \multirow[t]{2}{*}{ Process } & \multicolumn{3}{|c|}{ No of samples } & \multicolumn{2}{|c|}{ Mean concentration of $\mathrm{BeO}\left(\mu \mathrm{g} \mathrm{m}^{-3}\right)$} \\
\hline & Total & $>2 \mu g m^{-3}$ & $>25 \mu \mathrm{g} \mathrm{m}^{-3}$ & 1952 & 1960 \\
\hline \multicolumn{6}{|l|}{$\mathrm{Be}(\mathrm{OH})_{2}$ production } \\
\hline Kilns & 131 & 13 & 0 & $1 \cdot 00$ & $0 \cdot 40$ \\
\hline Crude hydroxide plant & 327 & 28 & 3 & $1 \cdot 00$ & $0 \cdot 25$ \\
\hline Final hydroxide plant & 120 & 21 & 1 & $2 \cdot 00$ & 0.40 \\
\hline \multicolumn{6}{|l|}{ Be metal production } \\
\hline General area & 241 & 36 & 4 & - & 0.57 \\
\hline Metal milling & 395 & 26 & 0 & - & $0 \cdot 40$ \\
\hline Slip-casting bay & 2233 & 153 & 11 & $0 \cdot 10$ & $0 \cdot 50$ \\
\hline \multicolumn{6}{|l|}{ Other buildings } \\
\hline Laboratory & 73 & 2 & 0 & - & 0.06 \\
\hline Laundry & 54 & 6 & 0 & $0 \cdot 24$ & $0 \cdot 30$ \\
\hline Changing area & 168 & 28 & 1 & 0.90 & 0.50 \\
\hline Offices & 55 & 0 & 0 & 0.08 & $0 \cdot 22$ \\
\hline Whole works & 3401 & 318 & 20 & 0.80 & 0.40 \\
\hline
\end{tabular}

The men exhibited a wide range of exposures (figs $1-3)$. The integrated dose index ranged from 0.49 $\mu \mathrm{g}$ months with a median of $8 \mu \mathrm{g}$ months, and the months of exposure and total dose indices were fairly highly correlated with it. The empirical clinical grading of exposure was weakly correlated with the integrated dose. It was nearly independent of the months of exposure.

CONFIRMED OR SUSPECTED BER YLLIUM DISEASE The clinical, radiographic, and physiological study in 1963 found six cases of definite, possible, or doubtful beryllium disease. The radiographic changes and, where present, the clinical features developed after the men had ceased to be exposed to beryllium. Cases 1 and 2 showed typical radiographic and lung function

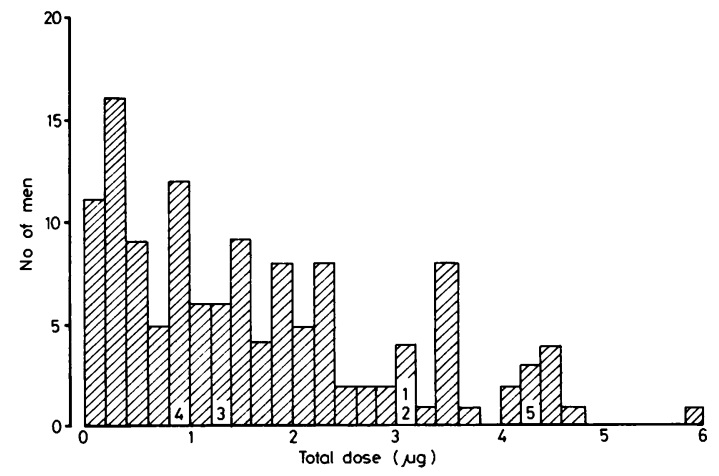

Fig 2 Distribution of men with respect to total dose of beryllium including those who developed beryllium disease without further exposure (cases 1-5).
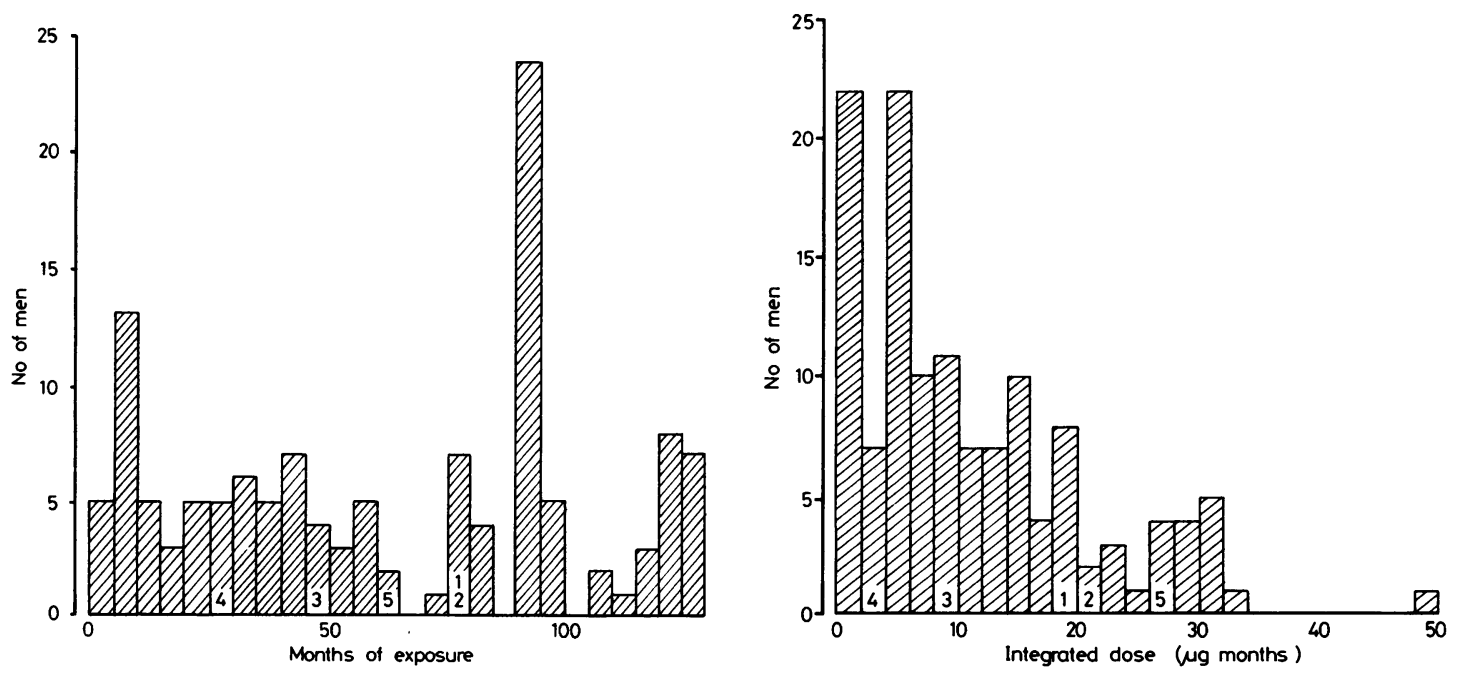

Fig 1 Distribution of men with respect to months of exposure including those who developed beryllium disease without further exposure (cases 1-5).

Fig 3 Distribution of men with respect to integrated dose of beryllium including those who developed beryllium disease without further exposure (cases 1-5). 
changes, though both men were asymptomatic at the time of diagnosis. In case 1 the results of the clinical and routine biochemical examination were negative. Case 2 gave a history of dermatitis and had a slightly raised serum gammaglobulin concentration; a few rales were heard on auscultation of the chest. He gave a history of haemoptysis for which no cause was found. Case 3 also had typical features at the time of assessment and, while no evidence was found at necropsy of residual beryllium disease the diagnosis was not seriously in doubt. Case 4 had typical small opacities on the chest radiograph for which there was no obvious alternative cause and a somewhat reduced transfer factor but was at the time and remained asymptomatic. Case 5 was classified as normal in 1963; however, a routine chest radiograph in 1965 first showed the small opacities present in subsequent films. One man had borderline radiographic abnormality at first examination but was classified as normal and remained asymptomatic despite continuing employment in the factory. He is not considered further. None of these men could recall any accident or other occasion when they were exposed to a high concentration of beryllium. Two men from among the 17 who did recall such episodes reported sick and experienced symptoms including pronounced shortening of breath and had patchy consolidation of the lung radiographically; these findings were consistent with acute beryllium pneumonitis. Both men had normal findings in 1963. No association could be detected between smoking habits and chronic beryllium disease.

The follow-up studies in 1973 and 1977 did not find any new cases. Two further men (cases 6 and 7), however, developed the typical features of subacute beryllium disease respectively in 1976 and 1981. Both men had worked in the factory for the whole of the period under review. In case 6 the test results up to and including 1974 were completely normal. The patient recalled an episode of high exposure in 1953 and developed symptoms after a beryllium patch test (not done by the investigators) in the autumn of 1976. Case 7 was asymptomatic and had normal lung function in 1977 but the chest radiograph showed simple pneumoconiosis. The symptoms developed after withdrawal from exposure.

All the men identified as possibly having beryllium disease had been exposed to beryllium oxide or hydroxide. Cases 1, 2, 6, and 7 were exposed to beryllium oxide in the slip-casting bay; cases 3 and 5 were exposed to beryllium hydroxide. Case 4 , a fitter, had worked throughout the plant. The estimated exposure of these men compared with others over the period up to 1960 , when most of them left the factory (figs 1-3) varied over a wide range. It was slight for cases 3,4 , and 7 , intermediate for cases 1 and 2 , and high for cases 5 and 6 . The corresponding indices for men who worked only in the slip-casting bay are shown in fig 4.

\section{LUNG FUNCTION; RELATION TO THE ESTIMATED EXPOSURE TO BERYLLIUM}

\section{Cross-sectional data}

The results of the assessment of the lung function made in 1963 have been examined in relation to the age and stature of the men and to their estimated exposure to beryllium. The average results for the different exposure groups are given in table 4 , which also shows expected values for healthy men of a mean age and stature similar to that of the subjects in exposure grade 0 . The more heavily exposed subjects

Table 4 Details of subjects and mean values for indices of lung function subdivided by grade of exposure: the reference values are for subjects of the mean age and stature of those in grade 0

\begin{tabular}{|c|c|c|c|c|c|}
\hline & \multicolumn{4}{|c|}{ Grade of exposure } & \multirow{2}{*}{$\begin{array}{l}\text { Reference } \\
\text { valuet }\end{array}$} \\
\hline & 0 & $I$ & 2 & 3 & \\
\hline 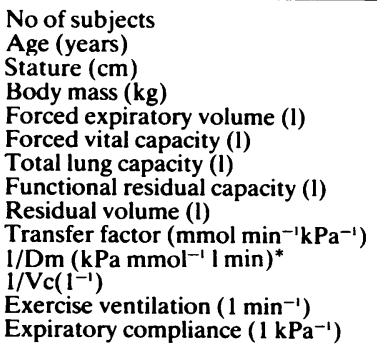 & $\begin{array}{c}17 \\
48 \cdot 4 \\
175 \cdot 5 \\
75 \cdot 1 \\
3 \cdot 22 \\
4 \cdot 31 \\
6 \cdot 22 \\
3 \cdot 11 \\
1 \cdot 88 \\
9 \cdot 70 \\
6 \cdot 90 \\
18 \cdot 54 \\
40 \cdot 0 \\
2 \cdot 42\end{array}$ & $\begin{array}{c}29 \\
43 \cdot 7 \\
175 \cdot 5 \\
71 \cdot 0 \\
3 \cdot 29 \\
4 \cdot 55 \\
6 \cdot 68 \\
3 \cdot 66 \\
2 \cdot 25 \\
9 \cdot 95 \\
7 \cdot 11 \\
16 \cdot 82 \\
31 \cdot 0 \\
2 \cdot 77\end{array}$ & $\begin{array}{c}66 \\
42 \cdot 3 \\
175 \cdot 4 \\
74 \cdot 8 \\
3 \cdot 49 \\
4 \cdot 76 \\
6 \cdot 91 \\
3 \cdot 47 \\
2 \cdot 10 \\
10 \cdot 35 \\
6 \cdot 11 \\
17 \cdot 98 \\
33 \cdot 3 \\
2 \cdot 67\end{array}$ & $\begin{array}{c}17 \\
40 \cdot 4 \\
174 \cdot 0 \\
75 \cdot 3 \\
3 \cdot 52 \\
4 \cdot 60 \\
6 \cdot 37 \\
3 \cdot 00 \\
1 \cdot 91 \\
10 \cdot 21 \\
6 \cdot 20 \\
14 \cdot 66 \\
33 \cdot 4 \\
2 \cdot 50\end{array}$ & $\begin{array}{c}3 \cdot 46 \\
4 \cdot 48 \\
6 \cdot 77 \\
3 \cdot 71 \\
1 \cdot 69 \\
10 \cdot 0 \\
6 \cdot 4 \\
11 \cdot 62 \\
35 \\
2 \cdot 7\end{array}$ \\
\hline
\end{tabular}

${ }^{*}$ For definitions see methods.

†From reference 8 . 

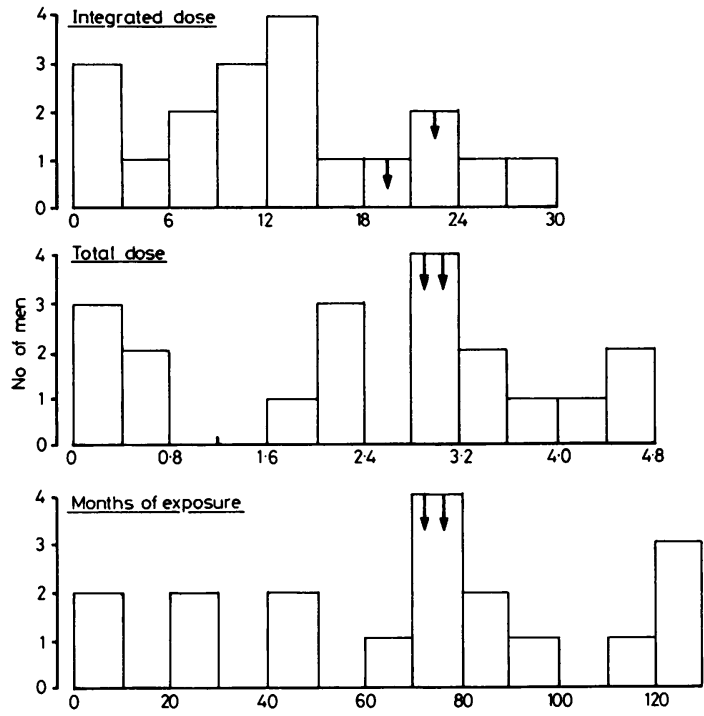

Fig 4 Distribution of 19 workers in slip-casting bay with respect to three indices of exposure to beryllium. The exposure groups of cases 1 and 2 are indicated by arrows. See also figs $1-3$.

were on average younger. The tests showed that the lung function of the defined population was that expected for the general population; there was no evidence for a decline in lung function with increasing exposure, but this analysis does not allow for the differences in age between the groups. The relation of the lung function to the estimated exposure to beryllium was assessed by multiple regression analysis; the regressors were age, stature, body mass, the exposure indices, whether or not the subjects were current smokers, and an interaction term reflecting the possibility that the decline in function with age might be greater in the smokers. The results are summarised in table 5 . The expected relationships of lung function to stature and to age are shown, though in three instances the deterioration with age is apparent only in the smokers. For the latter the accelerated decline is superimposed on initially superior function which is in line with expectation. Some of the variability between subjects is also related to body mass; for the residual volume and the expiratory reserve volume the association is a negative one, but the inspiratory capacity (IC) and the KCO (transfer factor per litre of lung volume) show a positive association.

The effect of exposure was obtained after allowing for all these factors. Increased exposure was associated with a relatively large vital capacity and tidal volume during exercise $\left(\mathrm{Vt}_{130}\right)$; there was no significant association with any other index. For the 19 men whose work was located entirely in the slipcasting bay the static compliance of the lung on expiration standardised for age and stature was found to be negatively correlated with exposure as estimated by the total and integrated dose indices (table 6, figs 5 and 6).

\section{Longitudinal data}

The changes in lung function for the defined population over the 10 years were regressed on stature, body mass, and age in 1963, the estimated exposure to beryllium, and whether or not the subject smoked (table 7). The forced vital capacity declined faster in the older subjects, forced expiratory volume declined faster in smokers than in non-smokers, and significant associations with estimated exposure were obtained for the forced expiratory volume and for the tidal volume at a constant minute volume during exercise. In both instances the decline with age was less for the subjects having the higher exposures to beryllium.

Table 5 Summary of results of multiple regression analysis of lung function on age, stature (St), body mass (M), exposure (Exp), and smoking (S)

\begin{tabular}{|c|c|c|c|c|c|c|c|}
\hline \multirow[t]{2}{*}{ Index } & \multicolumn{7}{|c|}{ Significant partial correlations $(p=0.05)$} \\
\hline & No & Age & St & $M$ & $\operatorname{Exp}$ & $S$ & Age $\times S$ \\
\hline FEV & 129 & - & + & & & & \\
\hline $\mathrm{FVC}^{\prime}$ & 129 & - & + & & + & & \\
\hline FEV\% & 129 & - & & + & & & \\
\hline IC & 122 & & + & + & & + & - \\
\hline ERV & 122 & & + & - & & & \\
\hline $\mathrm{RV}$ & 122 & + & + & - & & $\ddagger$ & \\
\hline TLC & 122 & $T$ & + & & & + & - \\
\hline Tlco,sb & 116 & & + & + & & + & - \\
\hline$\dot{\mathrm{V}}_{\mathrm{E}}, \mathrm{ex}$ & 95 & & & & & & \\
\hline $\mathrm{Vt}_{\mathrm{t}_{30}}$ & 95 & & & & + & & \\
\hline
\end{tabular}

$\ddagger$ Positive if body mass omitted. + Correlation positive. - Correlation negative. 


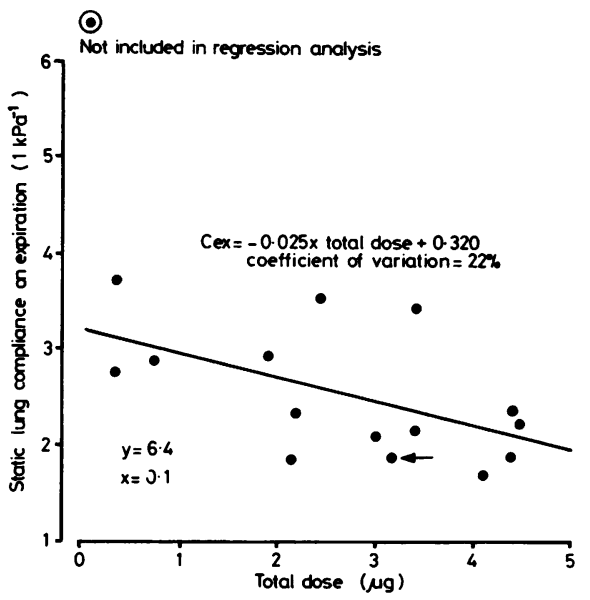

Fig 5 Relation of lung compliance to total dose of beryllium for 16 men who worked only in slip-casting bay. Case 1 is indicated by the arrow. Compliance was not obtained for case 2.

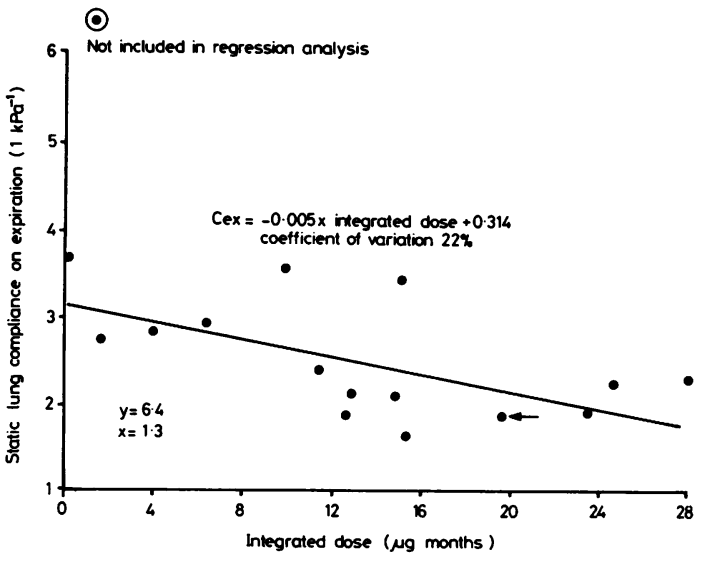

Fig 6 Relation of lung compliance to integrated dose of beryllium for 16 men who worked only in slip-casting bay. Case 1 is indicated by the arrow. Compliance was not obtained for case 2.
Table 7 Changes over 10 years in 79 subjects

\begin{tabular}{lll}
\hline Index & Change & Factors affecting \\
\hline Body mass & $+0.37 \mathrm{~kg}(\mathrm{NS})$ & \\
Stature & $-0.025 \mathrm{~m}$ & \\
FEV & $-0.0341, \mathrm{a}^{-1}$ & Smoking, exposure (+) \\
FVC & $-0.0301, \mathrm{a}^{-1}$ & Age in 1963 \\
VC & $+0.0211, \mathrm{a}^{-1}$ & \\
RV & $+0.0161, \mathrm{a}^{-1}$ & \\
KCO & $-0.008 \mathrm{SI}^{-1} \mathrm{a}^{-1}$ & \\
$\mathrm{~V}_{\mathrm{E}}, \mathrm{ex}$ & $+0.131 \mathrm{~min}^{1}, \mathrm{a}^{-1}$ & \\
$\mathrm{fC}_{\mathrm{i}}$ ex & $+0.66 \mathrm{~min}^{-1}, \mathrm{a}^{-1}$ & \\
$\mathrm{Vt}_{30}$ & $+0.0071, \mathrm{a}^{-1}(\mathrm{NS})$ & Exposure (+) \\
\hline
\end{tabular}

NS = Not significant; SI mmol $\mathrm{min}^{-1} \mathrm{kPa}^{-1} \mathrm{1}^{-1}$.

\section{Discussion}

The present study was directed to assessing the adequacy of the current beryllium hygiene standards for protecting workers from beryllium disease; a subsidiary aim was to find out if complete lung function tests will detect the effects of beryllium exposure before there is evidence of clinical or radiographic abnormality. The realisation of these aims depended on there being evidence of pulmonary damage due to beryllium among the defined population. In the event there were four definite clinical cases $(1,2,6$, and 7$)$, one highly probable case (3), and two cases of radiographic abnormality (4 and 5). Case 6 differed from the others in having a much bigger and more protracted exposure, and the disease appeared after the performance of a beryllium patch test, which may have been a contributory factor.' Cases 1 and 2 were found to have impaired lung function and radiographic abnormality some months after they had left the factory. The previous chest radiographs and the routine periodic clinical assessments, which for case 2 were conducted with particular care on account of his having had dermatitis, suggested that the disease developed soon after withdrawal from exposure. In case 3 symptoms developed during exposure and were ameliorated by steroid treatment in high dosage. The treatment probably contributed to the fatal outcome; it may also have led to the reversal and disappearance of the pulmonary pathology.

Table 6 Regression coefficients of lung function on age, stature and one of three indices of exposure for men whose work in the factory was confined to the slip-casting bay

\begin{tabular}{|c|c|c|c|c|c|}
\hline & \multirow[t]{2}{*}{ Age (a) } & \multirow[t]{2}{*}{ Stature $(\mathrm{cm})$} & \multicolumn{3}{|c|}{ Exposure index } \\
\hline & & & (I) & (2) & (3) \\
\hline $\begin{array}{l}\mathrm{FEV}_{1}(\mathrm{ml}, \mathrm{n}=19) \\
\operatorname{TLC}(\mathrm{ml}, \mathrm{n}=19) \\
\mathrm{T}^{\prime}\left(\mathrm{mol} \mathrm{min}^{-1}, \mathrm{kPa}^{-1}, \mathrm{n}=18\right) \\
\mathrm{C}_{\mathrm{E}}\left(\mathrm{ml} \mathrm{kPa}^{-1}, \mathrm{n}=15\right)\end{array}$ & $\begin{array}{l}-26 \\
\text { NS } \\
\text { NS } \\
\text { NS }\end{array}$ & $\begin{array}{l}\text { NS } \\
111 \\
\text { NS } \\
\text { NS }\end{array}$ & $\begin{array}{r}-1 \\
14 \\
0 \\
-10\end{array}$ & $\begin{array}{l}-50 \\
381 \\
-307 \\
-240^{*}\end{array}$ & $\begin{array}{l}-23 \\
12 \\
-106 \\
-42^{*}\end{array}$ \\
\hline
\end{tabular}

${ }^{*} p=0 \cdot 05$. 
The men who worked in the slip-casting bay showed a significant negative correlation between the estimated exposure to beryllium and the distensibility of the lung. This was the only evidence that lung function abnormality might precede radiographic abnormality. A decrease in lung compliance, however, was not a consistent feature of deterioration in cases studied clinically (paper in preparation), the association was not apparent in the follow-up study, and none of the men with a low compliance subsequently developed the disease, thus the finding was probably a chance association. By contrast there were two cases with isolated radiographic abnormality as well as four in whom both the chest radiograph and the lung function were abnormal. These and related observations suggest that while the lung function may contribute to diagnosis and management of suspected clinical cases it is much less useful than radiography for routine surveillance.

The evidence on beryllium hygiene conditions relates to environmental concentrations of beryllium oxide as no personal monitoring was carried out. The dust measurements were reproducible, and we are satisfied that every effort was made to see that they were representative of conditions in the factory: they were not directed to specific sources of dust production.

The average environmental concentration of beryllium, expressed as beryllium oxide, over the study period was usually below and never exceeded the AICGH threshold limit value (TLV). In some localities the total concentration of particles was higher due to the presence of dusts not containing beryllium; in addition in some instances the actual concentrations of oxide were considerably less than those reported owing to the presence of other constituents of beryllium ore. In the slip-casting bay, however, the exposure was due entirely to beryllium oxides, and of the 19 men who worked there continuously, two developed the disease soon after moving to other jobs. Thus the present TLV as related to the geometric mean concentrations obtained by static environmental sampling does not protect fully against berylliosis. Use of the geometric mean concentration minimises the contribution of the occasional high exposure in favour of those that occur most frequently, but this was probably not a source of error since only two cases of acute berylliosis due to high concentrations of beryllium occurred, and these men, and others similarly exposed, did not develop chronic beryllium disease over the period of the study. The use of personal monitoring might have led to a different result, but the readings would have needed to be on average five times higher than those actually recorded to produce an exposure above the
TLV, and for particles in the respirable range this seems unlikely.

The present threshold limit was proposed at a time when there was no direct evidence on which to base it; in addition the techniques for control of the environmental concentrations were relatively unsophisticated and lower concentrations difficult to achieve. Now there is both evidence and the means to achieve lower concentrations of environmental beryllium oxide so there is a strong case for the threshold being reviewed. When this is done, however, the criteria need to take into account the factors that influence the initial development of the disease. In particular it is desirable to know if there is a dose-response relationship such as would provide a definition of risk and permit choice as to what risk is acceptable. The present results are ambiguous on this point; for those up to 1963 there is no significant relationship unless case 6 is included, but this is not appropriate for the reasons given above. In addition the dust figures are possibly slightly misleading to the extent that not all the material identified spectrographically as beryllium is in a biologically active form. This limitation does not apply to the slip-casting bay, but only 19 men had a pure exposure. Cases 1 and 2 were among the top $25 \%$ of exposures when this was estimated as integrated dose, but not as total dose or months of exposure. If, as seems intuitively likely, the former index is the most appropriate then a relationship to dose is probable though not proved.

Evidence from earlier studies on man as well as animal experiments suggests a role for trigger factors; these include pregnancy, withdrawal from exposure $^{1011}$ and the performance of a beryllium patch test. The latter two procedures could have been precipitating factors in the present series. There is also a possible role for individual susceptibility, though the level of exposure at which it occurs and the associated immunological traits are not known. More information on the latter including immunological studies now in progress might permit the prior identification of those who are at special risk. In its absence there is need to look more closely at the unpublished evidence on dose-response relationships and to suggest guidelines for a lower threshold; however, at the present time what this should be can only be established by guesswork.

We are greatly indebted to the management and employees of the Consolidated Beryllium Co factory at Milford Haven for their co-operation in the study over many years, including in particular $\mathrm{Mr} \mathbf{P} \mathbf{R}$ Evans who provided much of the information for the indices of exposure and Mr E J Hannaford who arranged time off for personnel to attend for 
assessment. Dr Harold Davies, HM Inspector of Factories, introduced the problem to us, Dr H L Hardy encouraged us to tackle it, and Dr Leighton Davies, works medical officer, contributed wholeheartedly and disinterestedly to its solution. We are also indebted to colleagues at the Pneumoconiosis Unit for their help including Mr W G Clarke, Miss S Latham, Mr W P Audsley, Dr H Cockburn, Dr A T Axford, Miss A Davies, Mrs C John, Mr M J Saunders, Mrs C Bevan, Miss J M Dabbs, Dr P C Elmes, Dr A E Cockcroft, Miss M Gregory, and many others.

Part of the work was supported by a commission to the Medical Research Council from the Department of Employment.

Requests for reprints to: $\mathrm{Dr} \mathrm{J}$ E Cotes, University Department of Occupational Health, 21 Claremont Place, Newcastle upon Tyne NE2 4AA.

\section{References}

' Stokinger HE, ed. Beryllium. Its industrial hygiene aspects. New York: Academic Press, 1966.
${ }^{2}$ United States Environmental Protection Agency. Beryllium and air pollution: an annotated bibliography. North Carolina, USA: Air Pollution Central Office, 1971. (Publication AP;83.)

${ }^{3}$ Axford AT, Cotes JE, Gilson JC. Ten-year follow-up of three patients with beryllium disease (abstract). Thorax 1976;31:4912.

${ }^{4}$ Cotes JE, Gilson JC, Oldham PD, McKerrow CB, Davies H. Beryllium disease: relation of clinical, physiological and radiographic features to the estimated exposure to beryllium (abstract). Am Rev Respir Dis 1978;117, suppl:228.

${ }^{5}$ Medical Research Council. Standardised questionnaires on respiratory symptoms. $\mathrm{Br}$ Med J 1960;ii: 1665 .

- International Labour Office. U/C international classification of radiographs of pneumoconioses, 1971. Geneva: ILO, 1972. (Occupational safety and health, new series 22.)

' Roughton FJW, Forster RE. Relative importance of diffusion and chemical reaction rates in determining rate of exchange of gases in the human lung. J Appl Physiol 1957;11:290-302.

${ }^{8}$ Cotes JE. Lung function assessment and application in medicine. 4th ed. Oxford: Blackwell Scientific Publications, 1979.

' Waksman BH. The diagnosis of beryllium disease with special reference to the patch test. Archives of Industrial Health 1959;19:154-6.

${ }^{10}$ Hardy HL, Tabershaw IR. Delayed chemical pneumonitis occurring in workers exposed to beryllium compounds. Journal of Industrial Hygiene and Toxicology 1946;28:197-211.

"Schepers GWH, Durkan TM, Delahaut AB, Creedon FT. The biological action of inhaled beryllium sulfate: a preliminary chronic toxicity study on rats. Archives of Industrial Health 1957; 15:32-58. 